Norfolk and Wisbech Area Health Authority in 1985, uncertainty has surrounded the issue of confidentiality. While most doctors will respect the confidentiality of those seeking contraceptive advice, the suspicion has remained that a few, because of their personal beliefs, would breach confidentiality in the case of someone under 16.

The difficulty for the young person lies in distinguishing between those doctors they can and cannot trust. The consequences of such a breach of confidentiality might well be devastating for young people, and the chances of their pursuing a complaint against the doctor would be minimal. The General Medical Council's guidelines on confidentiality do not deal specifically with young people and contraception but emphasise that information about a patient should be disclosed without consent only in the most exceptional circumstances. $^{9}$ An explicit statement of what represents acceptable professional practice in the specific instance of a patient under 16 seeking contraception has, however, been lacking.

The BMA, General Medical Services Committee, Brook Advisory Centres, Family Planning Association, and the Royal College of General Practitioners have now filled the gap. In a joint guidance note to be sent to all general practitioners next week they spell out in unequivocal terms that disregarding confidentiality in such circumstances is a serious breach of professional ethics. What is now required is a communications strategy so that young people will know that they can put their trust in doctors irrespective of whether they work in general practice, family planning clinics, or Brook Advisory Centres.

Although progress is being made in medical confidentiality, a more sinister threat has arisen in the form of intimidation of those attending contraceptive services for young people. Premises have been picketed, and there have been threats to photograph those attending. This repulsive practice started in Belfast with the opening of a Brook Advisory Centre in September 1992 and now occurs in several cities across Britain. Such intimidation of young people seeking medical help is unacceptable in a civilised society and must not be allowed to succeed.

GABRIEL SCALLY Regional director of public health

South East Thames Regional Health Authority,

Bexhill-on-Sea,

Sussex TN39 3NQ

Department of Health. Health of the Nation. London: HMSO, 1992. (Cm 1986.)

2 Welsh health planning forum. Protocol for investment in health gain: healthy living. Cardiff: Welsh Office/National Health Service Directorate, 1993.

3 Department of Health and Social Services. Health and personal social services-a Northern Ireland strategy. Belfast: DHSS, 1992.

4 Jones E, Forrest JD, Goldman N, Henshaw SK, Lincoln R, Rosoff JI, et al. Teenage pregnancy in developed countries: determinants and policy implications. Family Planning Perspectives 1985;17:53-63.

World Health Organisation/International Federation of Gynaecology and Obstetrics. Task force on maternal and child health/family planning in primary care. Focus: teenage sexuality. Int Gynaecol Obstet 1990;32:81.

6 World Health Organisation/United Nations Fund for Population Activities/Unicef. The reproductive health of adolescents: a strategy for action. Geneva: WHO, 1989.

7 Allen I. Family planning and pregnancy counselling projects for young people London: Policy Research Institute, 1991.

8 Department of Health. HIVIAIDS and sexual health. London: DoH, 1993.

9 General Medical Council. Guidance for doctors on professional confidence. London: GMC, 1991

\title{
Junior doctors and the EC draft directive on working hours
}

\author{
Britain should not have sought to exempt juniors
}

According to a grand jury in New York County, Libby Zion, who died a few hours after admission to hospital, might have survived had she "received the experienced and professional medical care that should be routinely expected at hospitals such as the one involved." New York State's Court of Appeals decided that the two residents who had been on duty should not be charged with gross negligence. ${ }^{2}$ At the time of Libby Zion's death they had been on duty for 36 hours. The grand jury regarded the problem as "systemic"; it criticised the state for allowing overworked interns to make major decisions in the emergency room.

In response a committee was set up, which recommended that the state should limit the maximum number of hours that interns could work. An editorial in the fournal of the American Medical Association commented: "Until recently, many defended the residency system as good for medical education and patient care, without scientific support for their beliefs. We now hear we should study the problem before making changes, but we cannot wait for studies to resolve all remaining questions-now is the time for action." According to the journal, reducing hours of work was the single most important way of reducing stress. ${ }^{3}$

Over recent years junior doctors' hours have been reduced in Britain. In September 1990, for example, there were 13328 posts where the doctors were contracted to work over 83 hours a week compared with 370 in March this year (in many posts, however, doctors are working more than their contracted hours ${ }^{4}$. . Yet, at Britain's behest, the European Council of Ministers decided earlier this year to exempt doctors in training from the directive on working hours. Why did the British government invest so much of its prestige to prevent junior doctors from receiving the same protection given to the bulk of the European workforce? To ensure the safety and health of community workers the directive argues for a limit on maximum working hours and the granting of minimum daily, weekly, and annual periods of rest and adequate breaks. ${ }^{5}$

The need to ensure the quality of junior doctors' training is hardly likely to explain Britain's request for exemption: this concern is expressed in medical rather than government circles (and by seniors rather than juniors). The onus should be on those who argue that long hours are necessary for training to provide convincing evidence. Other European countries manage to train their doctors in a much less onerous fashion-for example, in Denmark, Norway, and Sweden junior doctors work 37-45 hours a week, and in the Netherlands they are limited to 48 hours. Moreover, the quality of postgraduate training is not ensured simply by long hours. Health and education authorities throughout Europe are increasingly trying to assure quality by deliberate measures such as setting standards, ensuring that the necessary facilities are available, and designing evaluation systems. Only once these measures have been implemented should we listen to claims that doctors have to work 65 hours a week in order to be properly trained.

The Danish labour minister, Jytte Andersen, chaired the meeting of the Council of Ministers that agreed the terms of the draft directive. In an interview with the fournal of the 
Danish Medical Association she said that she had sent a delegation to London to test the seriousness of the British demand to exempt doctors in training from the directive. ${ }^{6}$ Britain threatened to vote against the directive unless doctors in training were exempted. (As it was, Britain abstained from voting.) The British government advanced no specific arguments for its position. "We were in the position either of exempting doctors in training or of abandoning the directive," said Ms Andersen. "And since here we are talking only about a directive that sets up minimum requirements and does not change our options for maintaining the previous positions or improving them, we accepted." Later in the interview she said that the directive applied the moment a doctor finished his or her training: "It is exclusively doctors undergoing training who are exempted." If her interpretation is correct the doctors in training grade posts who have completed their specialist training would be covered under the terms of the directive.

According to rumours circulating in Brussels before the meeting, British officials had reportedly estimated the cost of not exempting British doctors in training as being $£ 100 \mathrm{~m}$. Money therefore seems the most likely explanation why junior doctors will not be covered by protective regulations that apply to other professionals in the health sector and to most other European employees. The Permanent Working Group of European Junior Hospital Doctors believes that it is unreasonable to exclude doctors in training, or anybody else in the health sector, from protective regulation when the only argument for doing so is cost. Junior doctors should be covered by the draft directive because it is in their interests and those of their patients.

JESPER POULSEN Chairman elect

Permanent Working Group of European Junior Hospital Doctors,

Danish Medical Assocation,

Copenhagen DK 2100,

Denmark

1 Wicker T. In the nation: blaming the system. New York Times $1987 \mathrm{Feb} 4$.

2 Page L. Doctors cleared in death that led to New York work rules American Medical News 1991 Nov 15:5.

3 McCall TB. No turning back: a blueprint for residency reform. JAMA 1989;261:909-10.

4 Meek C. Facing the future. BMA News Review 1993;19:19-21.

5 Council of the European Communities. Common position adopted by the Council with a view to the adoption of a directive concerning certain aspects of the organization of working time. Brussels: $\mathrm{EC}$, adoption of a directive concerning certain aspects
1993. (7253/93, soc 196, PRO-COOP 27.)

6 Rasmussen E. An example of cooperating Europe. An interview with Jytte Andersen, Danish minister of employment. Fournal of the Danish Medical Association 1993;155:2667-9.

\section{6 \\ Salt and asthma,}

\section{$A$ high salt diet may make asthma worse in men}

Evidence from several sources suggesting a relation between dietary consumption of salt and asthma raises several important questions. In particular, how hard are the data and should asthmatic patients restrict their salt intake?

Burney first suggested an association to explain the increased prevalence of asthma in communities adopting a Western lifestyle. ${ }^{1} \mathrm{He}$ found that regional sales of table salt in England and Wales correlated strongly with deaths from asthma in men and children. In a subsequent study of 138 men Burney and colleagues found a close relation between the results of a histamine challenge test and 24 hour urinary sodium excretion. ${ }^{2}$ Bronchial reactivity varied by a factor of 10 over the middle $95 \%$ of the range of sodium excretion. ${ }^{2}$ Several epidemiological studies since then have produced conflicting results, some showing a relation between asthma or bronchial reactivity and urinary sodium excretion or salt intake ${ }^{3}$ and others not. ${ }^{45}$

To differentiate between cause and effect, intervention studies modifying consumption of salt and monitoring bronchial responsiveness and severity of asthma were necessary. Several such studies have now been performed. In a small open study, doubling the intake of dietary salt for one month caused a modest increase in bronchial reactivity. ${ }^{6} \mathrm{~A}$ larger, randomised controlled trial of slow sodium showed an increase in bronchial reactivity in men but not women. ${ }^{7}$ The lack of a relation in women was consistent with the results of the study of deaths from asthma. ${ }^{1}$ Two studies looked at air flow and asthmatic symptoms with conflicting results. An open trial of a normal, low, or high salt diet in 17 subjects (nine men) found no relation between dietary consumption of salt and peak flow variability or use of $\beta$ agonists. ${ }^{8}$ In a larger, double blind study Carey et al studied 27 asthmatic men established on a low sodium diet before receiving $200 \mathrm{mmol}$ of slow sodium or placebo daily in random order. ${ }^{9}$ The low salt diet was associated with lower methacholine reactivity, consumption of bronchodilators, and symptom scores and higher peak flow and forced expiratory volume in one second. In comparison with the open trial, treatment in this trial was for longer, larger changes occurred in urinary sodium excretion, and only men were studied.

What could explain the fairly consistent relation between increasing sodium intake and worsening asthma in men but not women? In Blaustein's hypothesis for salt and hypertension a high salt diet increases the concentrations of circulating inhibitors of sodium-potassium ATPase, which then increase vascular responsiveness. ${ }^{10}$ Similar mechanisms would explain the relation between asthma and salt consumption, the difference being the end organ (airway smooth muscle or inflammatory cells rather than vascular smooth muscle). The sodium-potassium ATPase inhibitor ouabain contracts human airway smooth muscle ${ }^{11}$ but, unlike what happens with vascular smooth muscle, does not increase responsiveness to other spasmogens. There is evidence, however, that sodium-potassium ATPase may be reduced owing to increased circulating concentrations of inhibitors in atopic subjects, ${ }^{12}$ and ouabain increases the release of histamine by inflammatory cells. ${ }^{13}$ An increase in circulating sodium-potassium ATPase inhibitors due to an increase in salt intake may therefore increase inflammatory cell and hence airway responsiveness.

Another explanation is that the deterioration in asthma is due to the fall in circulating catecholamine concentrations that occurs with sodium loading. ${ }^{14}$ Changes in plasma adrenaline concentration modify bronchial reactivity ${ }^{15}$ and could account for up to half the change in bronchial reactivity that occurs with salt loading. Studies on skeletal muscle have suggested that women may have less sympathetic responsiveness than men, ${ }^{16}$ and studies in rats have shown sex differences in sodium-potassium ATPase activity. ${ }^{17}$ Either of these findings may explain why women are protected 